\title{
Initial experience with Thrombotest
}

\author{
A. L. Miller, G. FARRER-BROWN, AND J. PETHER \\ From the Courtauld Institute of Biochemistry, Middlesex Hospital Medical School, London
}

SYNOPSIS The initial experience of using Thrombotest instead of Quick's one-stage prothrombin time to control anticoagulant therapy is described.

Patients well controlled by the Quick test are often found to be over-anticoagulated by Thrombo- $-\frac{8}{0}$ test standards, so the introduction of Thrombotest has led to widespread reductions in dosage. No N improvement in stability of control has been noted. The main advantages of Thrombotest seem to $\vec{\infty}$ be its technical simplicity and the comparability of results obtained in different laboratories.

Until the beginning of 1962 anticoagulant therapy at this hospital was controlled by the Quick one-stage prothrombin time. The Thrombotest method of Owren (1959), however, seemed to offer certain advantages which have been well summarized by Fichera (1962). On theoretical grounds it has the advantage of alleged sensitivity to all the bloodclotting factors affected by oral anticoagulant drugs, prothrombin (factor II), proconvertin (factor VII), Christmas factor (factor IX), and Stuart-Prower factor (factor X). The Quick test is insensitive to changes in factor IX, so that any disproportionate fall in this factor during anticoagulant therapy would not be detected. Also it is sensitive to factor V, which is unaffected by anticoagulants. From the practical viewpoint, Thrombotest has the advantage of using a stable reagent, yielding a sharp, easily observed end-point. It gives reproducible results which are directly comparable with those obtained in other centres. It can be done on citrated plasma, but equally well on capillary or venous whole blood, thus eliminating the need for centrifuging. In some ways, therefore, it is simpler and more convenient. Its only practical disadvantage is the cost of the reagent.

Thrombotest has been in routine use here for over two years. This paper presents certain observations made during the early months after the change to this method.

\section{METHOD}

Blood for Thrombotest determination is taken by venepuncture into a plastic disposable syringe, and approximately $1.8 \mathrm{ml}$. immediately transferred to a polystyrene tube containing $0.2 \mathrm{ml}$. of $3.1 \%$ sodium citrate solution. Minor variations in the volume of blood added to the citrate do not affect the result obtained.

Received for publication 1 October 1963.
The test itself is carried out exactly as recommended by the vendors of the Thrombotest reagent. This is essential if reliable, reproducible results are to be obtained.

\section{THERAPEUTIC RANGE}

There is considerable discussion about the desirable therapeutic range for effective anticoagulant therapy. When using the Quick test results were expressed $\mathbb{Q}$ simply as a test/control ratio, and patients were $\Rightarrow$ considered satisfactorily anticoagulated with a prothrombin time of 2 to 2.5 times that of the control. Variation within the range 1.9 to 2.6 was tolerated without an immediate change in dose. The acceptable Thrombotest range quoted is 10 to $25 \%$.

Before changing to Thrombotest, 70 patients on long-term anticoagulant therapy were examined on $a^{3}$. single day by both methods. The results of this comparison are presented in Figure 1 . It became clear that the recommended levels for the two 3 methods of control do not represent the same level of anticoagulation. This was also the finding of Moore and Beeler (1961).

Only 10 patients were satisfactorily controlled by both standards. Of 34 patients judged to be wello controlled by the Quick test (2.0 to 2.5), 24 hade Thrombotest results of less than $10 \%$. On the othero hand, of 29 patients under-anticoagulated by the Quick test, 20 fell within the prescribed Thrombotest range.

The findings of this pilot trial were confirmed when Thrombotest was adopted as the routine method. Of 134 patients, who continued on the same dose during the changeover period, and who had a final $\mathbb{Q}$ prothrombin ratio of 2.5 or less, i.e., were wello controlled or under-anticoagulated by existing standards, $94(70 \%)$ were judged to be over-anti-o 


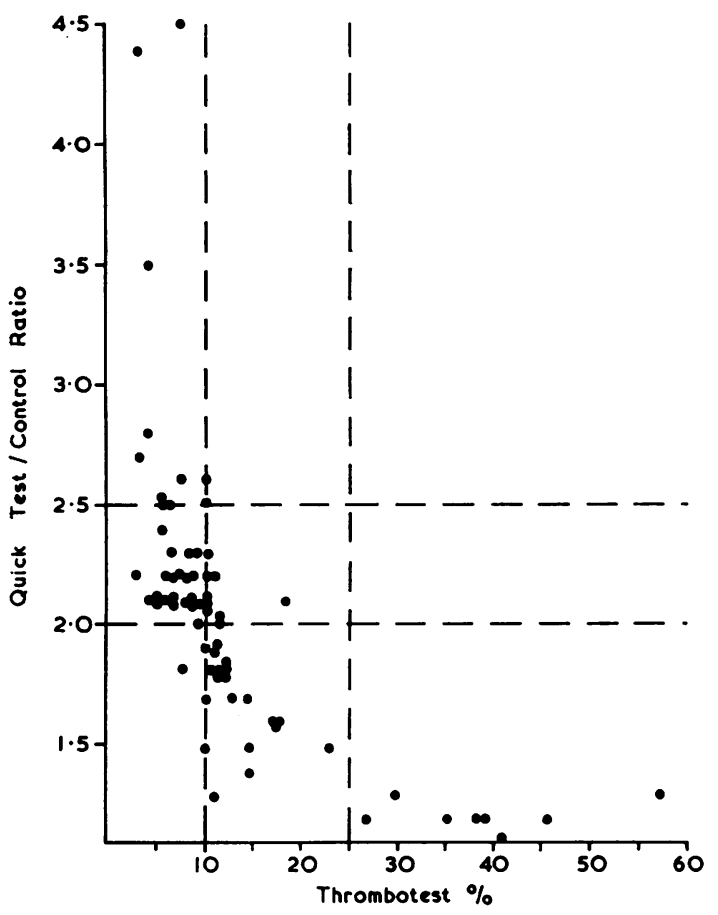

FIG. 1. Results of the initial comparison of the two tests in 70 patients.

coagulated after their first Thrombotest, having a result of $10 \%$ or less.

It was therefore necessary to define a therapeutic range for Thrombotest which would be acceptable in the light of previous experience of anticoagulant therapy. It was felt advisable to accept the lower limit of $10 \%$ suggested by Owren (1959), but the upper limit of $25 \%$ seemed to represent a level of anticoagulation which we had previously regarded as inadequate. It was decided to try to maintain patients within the narrow range of 10 to $15 \%$. As discussed later, this has proved difficult, and we have come to accept results in the range 8 to $20 \%$ without immediate change in dose.

\section{ANTICOAGULANT DOSAGE}

Adopting these new standards of control led to widespread reductions in dose in the early weeks, a sequel to the introduction of Thrombotest which has been noted elsewhere (Lancet, 1962). Figure 2 compares the dose of phenindione in 111 patients on 1 June 1961, when therapy was controlled by the Quick test, with their dose on 1 June 1962, when control by Thrombotest was well established. Some $80 \%$ of the patients were taking a lower dose, the mean reduction in dose being $23 \%$.

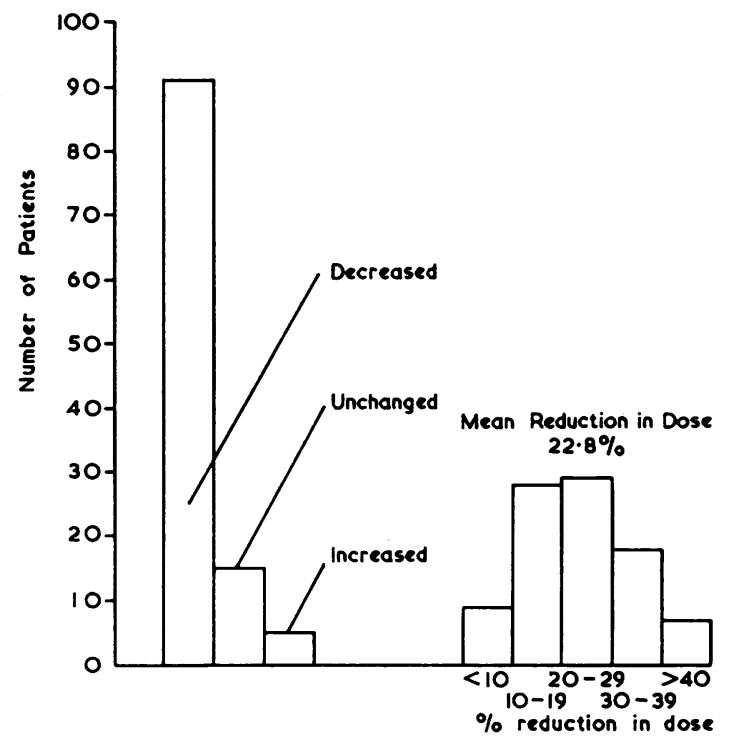

FIG. 2. Comparison of dose of phenindione in 111 patients on 1 June 1961 and on 1 June 1962.

\section{STABILITY OF CONTROL}

Table I summarizes the results of 1,597 Quick tests before the changeover and compares them with 1,370 Thrombotest results. It shows that we are less successful, using Thrombotest, in maintaining patients within our defined therapeutic range. More patients, however, now give a result within a range which is accepted without an immediate dose change ( 8 to $20 \%$ ) than was the case when the prothrombin time range tolerated was 1.9 to 2.6 . This may indicate acceptance of greater variation in the degree of anticoagulation than was previously permitted.

TABLE I

COMPARISON OF RESULTS WITH QUICK ONE-STAGE TEST AND THROMBOTEST

Quick One-stage Thrombotest
Prothrombin
Time

\begin{tabular}{lccc}
\hline $\begin{array}{l}\text { No. of tests } \\
\begin{array}{l}\text { Result within therapeutic } \\
\text { range }\end{array}\end{array}$ & 1,597 & 1,370 \\
$\begin{array}{l}\text { Result with temporarily } \\
\text { acceptable range }\end{array}$ & $(1 \cdot 9-2 \cdot 6)$ & $56.9 \%$ & $68.2 \%(8-20 \%)$ \\
$\begin{array}{l}\text { Result indicating under- } \\
\text { anticoagulation }\end{array}$ & $(<1.9)$ & $34.4 \%$ & $13.7 \%(>20 \%)$ \\
$\begin{array}{l}\text { Result indicating over- } \\
\text { anticoagulation }\end{array}$ & $(>2 \cdot 6)$ & $8.7 \%$ & $18 \cdot 1 \%(<8 \%)$ \\
$\begin{array}{l}\text { Result suggesting dangerous } \\
\text { haemorrhagic risk }\end{array}$ & $(>5.0)$ & $0.19 \%$ & $2.5 \%(<5 \%)$
\end{tabular}

The figures in brackets represent the appropriate ranges for the two tests. 
Table I also shows that the incidence of results suggesting potentially dangerous haemorrhagic risk has increased more than ten-fold. This might suggest that Thrombotest gives more significant warning of such risk. However, during the pilot trial of the two methods referred to above, urine specimens from all 70 patients were examined for blood, using Occultest (Ames). No patients had noticed blood in the urine, nor did any specimen show macroscopic haematuria. Four patients gave positive Occultest results, of which only one was strongly positive. This patient, who was feeling unwell and developed an overt chest infection the following day, had a Thrombotest result of $8 \%$ but a Quick ratio of 4.5. In this case at least, the Quick test gave the more dramatic warning of an unexpected and dangerous disturbance of control. Of the three patients with weakly positive tests for blood in the urine, none had a Thrombotest result of less than $8 \%$. Some caution is therefore necessary in assessing the relative merits of the two tests in predicting haemorrhagic risk.

\section{DISCUSSION}

Thrombotest is a technically simple and reproducible test for control of anticoagulants. The advantages of having results which are comparable with those obtained elsewhere are considerable both to the patient, who for a variety of reasons may need to be controlled temporarily at some other centre, and for research purposes. It also has the alleged advantage of detecting any disproportionate fall in factor IX, which would not be detected by the Quick test. However, this sensitivity to factor IX has been disputed by a number of workers (Nour-Eldin, 1959;
Denson, 1961 ; Quick and Hussey, 1961), and in any을 case the practical significance of such sensitivity in the control of anticoagulant therapy is uncertain.? Rapaport and Ames (1962) have produced evidence to show that bleeding secondary to an excessive depression of factor IX is unlikely to occur in patients who are well controlled using the Quick test.

The change to Thrombotest here has resulted in $\overrightarrow{0}$ acceptance of a lesser degree of anticoagulation withlower dosage in many patients. This presumablyc means that the haemorrhagic risk of therapy has been? reduced; there is as yet no evidence to show whether? patients are as adequately protected against re- $\overrightarrow{-}$ current thrombotic or embolic episodes.

For the present, there seems to be no advantage in $\overrightarrow{00}$ using Thrombotest for the control of anticoagulan ${ }^{N}$ therapy, other than the technical advantages of the ${ }^{-}$ method and the desirability of the introduction of $\vec{a}$ single widely adopted method for the control ofou these patients.

We would like to thank Miss Jean Wilkins and Dr. D. $H_{\mathscr{\circ}}$ Keeling who were together responsible for the smooth ${ }^{\circledR}$ introduction of Thrombotest into the Routine Laboratory, and also Professor Sir Charles Dodds for his interest in this work.

\section{REFERENCES}

Denson, K. W. (1961). J. med. Lab. Technol., 18, 257.

Fichera, C. (1962). Acta med. scand., 172, 363.

Lancet (1962). 2, 593.
Moore, C. B., and Beeler, M. F. (1961). New Engl. J. Med., 264, 681

Nour-Eldin, F. (1959). Lancet, 2, 913.

Owren, P. A. (1959). Ibid., 2, 754.

Quick, A. J., and Hussey, C. V. (1961). New Engl. J. Med., 265, 1286 ?

Rapaport, S. I., and Ames, S. B. (1962). Ibid., 267, 125. 